ORIGINAL ARTICLE

AFRICAN JOURNAL OF CLINICAL AND EXPERIMENTAL MICROBIOLOGY AJCEM/21307

COPYRIGHT 2013 http://dx.doi.org/10.4314/ajcem.v14i1.8

ANUARY2013 ISBN 1595-689X VOL 14(1) 2013

AFR. J. CLN. EXPER. MICROBIOL 14(1): 34-39

-http://www.ajol.info/journals/ajcem

\title{
ISOLATION OF ENTEROVIRUS FROM FEACAL SAMPLES OF PATIENTS WITH DIABETES MELLITUS IN MAIDUGURI, NIGERIA.
}

\author{
1,2 Oderinde,, B.S.*, 1,2 Baba M.M., ${ }^{1}$ Nwodo, M.U., ${ }^{2}$ Ladan, J., ${ }^{2}$ Musa, B.J., ${ }^{2}$ Ghamba, P.E., ${ }^{2}$ Akinola, M.T. \& ${ }^{2}$ Kadai, A.M. \\ 1. Department of Medical Laboratory Science, College of Medical Sciences. University of Maiduguri, P.M.B 1069 \\ Maiduguri, Borno State. Nigeria;
}

2. World Health Organization National Polio / ITD Polio laboratory, University of Maiduguri Teaching Hospital, P.M.B 1414 Maiduguri, Borno State. Nigeria.

Correspondence:: Oderinde B.S. Department of Medical Laboratory Science, College of Medical Sciences. University of Maiduguri, P.M.B 1069 Maiduguri, Borno State. Nigeria. E-mail: $\underline{\text { sojihunter@yahoo.com }}$

\begin{abstract}
In this study, 150 patients were recruited out of which $63(42 \%)$ were male while $87(58 \%)$ were female subjects. Patients with type 1 diabetes were 2(1.3\%), those with type 2 were 142(94.7\%) while those with GDM were $4(4 \%)$. Only one sample from type 2 was positive by virus isolation and identified to be Echovirus 1 and 21 by microneutralization tests as described in WHO polio laboratory manual, 2004. It has been demonstrated that enterovirus infections were significantly more common in recently diagnosed diabetic patients, compared to control subjects. The question if enterovirus could cause beta cell damage and diabetes mellitus has become more and more relevant when recent studies have provided new evidence supporting this scenario especially in type 1 diabetes. This is an important issue since it opens the possibility to develop new, preventive and therapeutic strategies to fight the disease. The purpose of this study is to investigate if enterovirus can be isolated from the stool samples of diabetic patients as a study.
\end{abstract}

Key words: Isolation, enteroviruses, faeces, diabetes mellitus, patients,

\section{INTRODUCTION}

Diabetes mellitus or diabetes is a lifelong chronic disease in which there is high level of sugar in the blood which results in symptoms such as blurry vision, excess thirst, fatigue, frequent urination, hunger and weight loss (1). There are three major types of diabetes mellitus: Type 1 diabetes mellitus can occur at any age but is most frequently diagnosed in children-teen or young adults. In this disease the body makes little or no insulin. Type 2 diabetes mellitus which makes up most diabetes cases. It most often occurs in adults (2). It results from insulin resistance; a condition in which cells fail to utilize insulin properly. Gestational diabetes: when pregnant women who have never had diabetes before have a high blood glucose level during pregnancy.

Globally, as of 2010, an estimated 285 million people had diabetes, with type 2 making up about $90 \%$ of the cases (3). Its incidence is increasing rapidly, and by 2030, this number is estimated to almost double (4). Diabetes mellitus occurs throughout the world, but is more common (especially type 2) in the more developed countries. The greatest increase in prevalence is, however, expected to occur in Asia and Africa, where most patients will probably be found by
2030. The increase in incidence in developing countries follows the trend of urbanization and lifestyle changes, perhaps most importantly a "Western-style" diet. This has suggested an environmental (i.e., dietary) effect, but there is little understanding of the mechanism(s) at present, though there is much speculation, some of it most compellingly presented (4).

The infection with enteroviruses seems to be linked to the induction of islet-cell autoantibodies as well as to the expression of interferon-á. Both of these events are connected with islet-cell destruction (5). It has become increasingly important to establish the nature of the infecting virus in the early stages of diabetes and seems a number of viruses of the coxsackie or echovirus type are involved, although the nature of the nucleotide sequences responsible for diabetogenicity remains elusive. Viruses have long been considered a major environmental factor in the aetiology of type 1 diabetes mellitus and recent work has greatly confirmed this role and now evident that enteroviral infections accompany the onset of diabetes in young people. It is only recently that clearer role of this virus in the aetiology of diabetes began to emerge despite large volume of work devoted to them.Diabetes 
mellitus has no doubt been on the increase for the past ten years in Nigeria. The national prevalence puts it at about $2.2 \%$ and this continues to be on the increase (6). Coxsackie B viruses are known to cause pancreatitis and diabetes in mice. There is some evidence that coxsackie B viruses, particularly B4, may play a role in the pathogenesis of juvenile onset IDDM. Post mortem studies on patients with diabetic ketoacidosis and seroepidemiological data have implicated coxsackie B viruses. $30 \%$ of children with IDDM have IgM antibodies to coxsackie B viruses compared to 5 - $8 \%$ for matched controls. It is probable that other cofactors are required.

The family under this genus include poliovirus, coxsackievirus, entero cytopathic human orphan (ECHO) virus and enterovirus. Some clinical syndromes associated with enteroviruses include paralytic diseases, meningo-encephalitis, diabetes/ pancreatitis, carditis, neonatal disease, etc. (7-9). Enteroviruses are spread via the faecaloral route.The primary replication of enteroviruses happens in the intestinal cells (10). Didier Hober (2010) in his experiment shows that CV-B and other enterovirus serotypes can infect and replicate in beta cells in- vitro. This infection and re-infection can initiate and accelerate beta cell impairment through the activation of antienteroviral $\mathrm{T}$ - lymphocytes.The detection of enterovirus in various tissues, blood, gut, and pancreas of patients with type 1 diabetes mellitus suggests an association between the virus and the disease. (12). Type 1 diabetes usually starts in young people and results from the destruction of insulin producing beta cells in the pancreas. An extension of the study showed that $40 \%$ of adults with type 2 diabetes have had infection in insulin producing cells i.e. beta cells (13). These beta cells are not destroyed in these diseases but their ability to make insulin is compromised. The way this enterovirus might contribute to the development of type 2 diabetes has not been established, but it's known from laboratory studies that an enteroviral infection of beta cells reduces their ability to produce insulin (14).

\section{Enterovirus and type 1 diabetes}

Type 1 diabetes usually starts in young people and results from the destruction of the insulinproducing beta cells in the pancreas. Enteroviruses infect the pancreas of patients; in addition, the infection of other tissues in human beings has been reported as well. The detection of enteroviruses in various tissues, blood, gut, and pancreas of patients with T1D suggests an association between these viruses and the disease (12).CV-B and other enterovirus serotypes can infect human islets and can replicate in $\beta$-cells in vitro, which stimulates the production of cytokines (soluble mediators of the "communication" between immune cells) and membrane proteins at the surface of $\beta$-cells that are able to intervene in pathogenic processes. $\mathrm{CV}$ B4 inoculated to mice resulted in diabetes with viral replication in $\beta$-cells. CV-B replicated in human $\beta$-cells in vitro. An expression of IFN-a by $\beta$-cells was observed (15). IFN- $\alpha$ can play a pathogenic role through induction of class I HLA molecules and ICAM- 1 at the surface of $\beta$-cells, which is a characteristic of $\beta$-cells of patients with T1D. It is interesting to note that transgenic mice whose $\beta$-cells express IFN-a develop diabetes as a result of insulitis and $\beta$-cell destruction, due to activation of autoimmune effector cells against islets (16). In addition, maternal enterovirus infections during pregnancy have been linked to an increased risk of type 1 diabetes in the offspring (17).

\section{Enterovirus and type 2 diabetes}

An extension of the study to adults with type 2 diabetes showed that a large proportion of the same age group. Unlike type 1 diabetes, type 2 diabetes usually starts in adults and is associated with obesity. The beta cells are not destroyed in this disease but their ability to make insulin is compromised. The way that enteroviruses might contribute to the development of type 2 diabetes has not been established but it is known from laboratory studies that an enteroviral infection of beta cells reduces their ability to release insulin. It is possible that in people who are obese (where there is a greatly increased demand for insulin secretion) a reduction of beta cell function, secondary to enteroviral infection, may be sufficient to trigger type 2 diabetes - although more research is required to confirm this.(18). Another recent study to be published in www.phgfoundation.org/news/4515/ proposed link between T1D and enterovirus infection which reports the detection of enteroviruses in pancreatic tissue from about $60 \%$ of 72 paediatric patients with T1D, but very few of the samples of tissue from 50 children without the disease (20). This research also found that $40 \%$ of adults with type 2 diabetes showed signs of enteroviral infection of their pancreatic beta cells, compared with only 13 percent of non-diabetic (control) adults of the same age. The authors propose that vaccination against enteroviral infection in childhood could reduce the incidence of both common forms of diabetes.

\section{MATERIALS AND METHODS}

\section{Study area:}

Stool samples were collected from adults who visited University of Maiduguri Teaching Hospital (UMTH), Maiduguri, Nigeria for medical attention and follow up treatments. The hospital is a tertiary 
health institution located in Borno State, Nigeria and serves as a referral health centre for six states (Adamawa, Bauchi, Borno, Gombe, Taraba and Yobe,) in northeastern Nigeria and neighboring African countries (Chad to the northeast, Niger to the north and Cameroon to the east). Based on the 2006 provisional census figures, Borno State has a population of 4,151,193 and a population density of approximately 60 inhabitants per square kilometer.The state has an area of $61,435 \mathrm{sq} . \mathrm{km}$ (the largest state in Nigeria in terms of land mass).(21).

\section{Study population:}

The Ethical Committee of University of Maiduguri Teaching Hospital, Maiduguri gave approval to the study protocol. Only patients with confirmed diabetes were recruited for the study. After obtaining informed consent from those subjects, willing participants were enrolled consecutively in the study. Demographic data were collected.

\section{History of the subjects studied:}

The record of the subjects tested was not available but information in this regard was obtained was verbal. However,

\section{Sample collection:}

A total of 150 stool samples were collected from the subjects studied between January and February 2012. Clean universal containers are given to each patient to be returned the next day with fresh fecal sample (about $2 \mathrm{~g}$ or the size of an adult thumb). The stool samples were properly labelled and transported to the World Health Organization National Polio Laboratory, Maiduguri for storage and analysis. The entire stools were stored at $-20^{\circ} \mathrm{C}$ until tested.

Virus Isolation and Identification / Microneutralization tests for Non Polio enteroviruses.
The methods adopted for virus isolation and microneutrlization for identification of isolates were described in WHO Polio Laboratory Manual (2004) and the supplemental manual of (2006) for the New Algorithm Technique currently used for poliovirus isolation. Feacal samples were pretreated with chloroform and phosphate buffered saline and centrifuged at $3000 \mathrm{rpm}$ for 30 minutes, $200 \mathrm{ul}$ of the supernatant was inoculated onto healthy monolayer of L20B and Rhabdomyosarcoma (RD) cell lines (Source: Centre for Disease Control and Prevention, Atlanta. USA) in maintainance medium (Eagle's MEM Supplemented with $2 \%$ Fetal Calf Serum (FCS). The cells were seeded 48 hours prior to inoculation with growth medium (Eagle's MEM supplemented with 10\% FCS). The inoculated monolayers were incubated at $36^{\circ} \mathrm{C}$ and observed daily for the characteristic enterovirus cytopathic effects (CPE) of rounded refractile cells and detaching from the surface of the tube. The tubes with CPE up to $75 \%$ and above were harvested and kept at $-20^{\circ} \mathrm{C}$ to be passaged to a fresh monolayer of the second cell line. While those negative after 5 days of incubation at $36^{\circ} \mathrm{C}$ were repassaged on the same cell line. Tubes showing no CPE after the second five days were considered as negative. With the New Algorithm Technique, Positive isolates usually end in RD cell line because virus titre seems higher in RD than L20B. Positive samples on RD cells were passaged onto L20B, the selective cell line for poliovirus. Identication of isolates on RD cells was carried out by microneutralization technique using antisera raised in horse against coxsackie and echoviruses prepared by the National Institute of Public Health and Enviroment (RIVM), Netherlands.

\section{RESULTS}

Students SPSS version 16 was used for the computation and the results obtained are below:

TABLE 1. NUMBER OF DIABETES TYPES WITH PERCENTAGES N=150.

\begin{tabular}{llc}
\hline Types of Diabetes & Number tested & Percentage (\%) \\
\hline Type 1 & 2 & 1.3 \\
Type 2 & 142 & 94.7 \\
Gestational diabetes (GDM) & 6 & 4 \\
Total & 150 & 100 \\
\hline
\end{tabular}

Table 1 presents the number and percentages of diabetic patients with the 3 types of diabetes. It is shown that type 2 is the most predominant with $142(94.7 \%)$, followed by gestational diabetes
(GDM) in 6(4\%) pregnant women and type 1 with lowest with $2(1.3 \%)$ patients.

Table 2 represents the age range of the 150 diabetic patients with number involved. Out of 150 
samples, 2(1.3\%) were less than 20years, $6(4.0 \%)$ were within the age group of $21-29,17(11.3 \%)$ were within 30-39, 49(32.9\%) within 40-49, $50(33.3 \%)$ within $50-59$, while $26(17.3 \%)$ were within 60 and above. It can be inferred that most diabetic onset starts the age of fourties. In addition the highest number of patients falls in the fifties as a result of ageing factors.

TABLE 2. AGE RANGE DISTRIBUTION OF DIABETIC PATIENTS N=150.

\begin{tabular}{lcc}
\hline Age groups (yrs) & Number (150) & Percentage (\%) \\
\hline$\leq 20$ & 2 & 1.3 \\
$21-29$ & 6 & 4.0 \\
$30-39$ & 17 & 11.3 \\
$40-49$ & 49 & 32.7 \\
$50-59$ & 50 & 33.3 \\
$60-69$ & 24 & 16 \\
$\geq 70$ & 2 & 1.3 \\
\hline Total & 150 & 100 \\
\hline
\end{tabular}

TABLE 3: DISTRIBUTION OF DIABETIC PATIENTS BY DURATION / ONSET

\begin{tabular}{lccc}
\hline Duration / Onset (yrs) & Number (150) & Percentage (\%) \\
\hline $1-5$ & 98 & 65.3 \\
$6-10$ & 32 & 21.3 \\
$11-15$ & 11 & 7.3 \\
$16-20$ & 4 & 2.7 \\
$21-25$ & 3 & 2.0 \\
$26-30$ & 2 & 1.3 \\
\hline Total & 150 & 100 \\
\hline
\end{tabular}

Table 3 shows the distribution of patients with the duration of onset of diabetes in years. Out of 150 patients whose samples were used, 98(65.3\%) have had diabetes for less than or equal to 5years, $32(21.3 \%)$ for about $6-10 y e a r s, 11(7.3 \%)$ for about 11-15years, $4(2.7 \%)$ for about 16 -20years, while $2(1.2 \%)$ have had it for about 26-30years.The highest figure obtained with onset of 1-5years might be due to increased publicity and awareness of the people. This reflects increase in number of diabetic patients with decreased year(s) of onset that seeks medical attention.

DISCUSSION Enteroviruses have long been considered a major environmental factor in the aetiology of diabetes mellitus (5). These viruses have been detected from diabetic patients more often than from control subjects and they can infect beta cells in cell culture and induce diabetes in animal models (23). A research conducted by Salminen (2004) in Finland on children between 618 years, revealed that enterovirus can be isolated in stool samples.

In this work, out of 150 samples collected 63(42\%) were male while $87(58 \%)$ were female subjects also, subjects with type 1 were $2(1.3 \%)$, type 2 were $142(94.7 \%)$ and GDM were $6(4 \%)$, this is owing to the fact that type 2 is the most common type which is due primarily to lifestyle modification, genetics and viruses (25). The only positive sample was from a male subject with type 2 diabetes and fell within the age bracket of 50-59 with duration of within 11-15 years. There is no related literature to justify why it was male and within that age group and the given duration. 
The Echovirus 1 and 21 that was isolated from the positive case might not be responsible for the aetiology of Type 2 diabetes as this may not be unconnected with the poor hygiene standards commonly observed in most communities as previously reported (26). In addition this serotypes were not among the ones isolated in aetiology of acute flaccid paralysis in northern Nigeria of which this study area was inclusive (27) meaning that further researches need to establish echovirus in aetiology of Type 2 diabetes. However, the fact that no absolute association has been identified with certain viral strains or even viral geniuses or families indicates that, if Type 1 diabetes is indeed caused by viruses, multiple infectious strains may result in the same disease phenotype (28). In conjecture, there is need for further researches at molecular level to establish this fact or probably the unbiased metagenomics techniques.

The Gestational Diabetes Mellitus (GDM) came into consideration as maternal enterovirus infection is a risk factor for Type 1 diabetes in the exposed offspring (17). This emphasizes the fact that pregnant women needs to be screened for enterovirus infection to carry out preventable measures before delivery of the offspring. In addition, there is need to implement health education in Antenatal clinics in this regards. There is no documented evidence regarding the association of enterovirus in the aetiology of Type 2 diabetes which form $94.7 \%$ of the patients tested, and no virus isolation was made. Considering the duration of the onset of the infection, 0-5 range has the highest with $68.8 \%$ which might not be unconnected with the increased awareness of the people even at the grass root level. However, more publicity is still required with the provision of basic care at the Primary Health Care facility which is supposed to be made available at the closest reach of every Nigeria. However, the timing cannot be underplayed as a component determining virally

\section{REFERENCES}

1. Van Belle TL., Coppieters KT.,Von Herrath MG. Type 1 diabetes: etiology, immunology, and therapeutic strategies. Phusiol Rev 2011; 91(1) 79-118

2. Alemzadeh R, Ali O. Diabetes Mellitus. In: Kliegman RM, ed. Kliegman: Nelson Textbook of Pediatrics. 19th ed. Philadelphia, Pa: Saunders; 2011:chap 583.

3. Williams textbook of endocrinology (12th ed.). Philadelphia:Elsevier/Saunders. pp. 1371-1435. ISBN 978-1-4377-0324-5.

4. Wild S, Roglic G, Green A, Sicree R, King H. "Global prevalence of

diabetes: estimates for 2000 and projections for 2030". Diabetes Care, 2004. 27 (5): 1047-53. mediated modulation of autoimmunity appears to be the time at which infection occurs during the prediabetic phase e.g. type 1 diabetes is enhanced in 8 week old NOD mice infected with Coxsackie B4, infection of younger mice has no effect on disease outcome which suggests that the status of autoimmune progression is a crucial determinant in the diabetogenic potency of the virus (29). The highest prevalence was within 50-59 years with $33.3 \%$, followed by $40-49$ years with $32.7 \%$ which of course might be due to ageing factor.

In conclusion, these patients samples based on retrospective study showed that they are diabetic patients. Only $1(0.6 \%)$ of the patient with type 2 diabetes stool sample were positive while $99.3 \%$ were negative. Based on this result it cannot be concluded that enteroviruses do not cause diabetes mellitus, various factors has to be considered such as; Type of diabetes, patients residence / environment, timing of infection and subjects hygiene standards enteroviral destruction of $\beta$-cells of the pancreas occurs years before clinical symptoms of diabetes appears. If samples were collected at onset of clinical symptoms then most of this virus could be isolated. In addition, there is need to establish the role of echovirus in the aetiology of diabetes by advanced unbiased metageomics technique, which will give a clearer information and data.

\section{ACKNOWLEDGEMENTS}

We thank the WHO for provision of technical support to the laboratory and management of University of Maiduguri Teaching Hospital (UMTH) for their contribution to the study by guiding and giving us ethical clearance.

5. Hyoity H, Taylor K.W. The role of viruses in human diabetes. Diabetologia, 2002. 45 : 1353 $-1361$.

6. Nyenwe EA, Odia OJ, Ihekwaba AE, Ojule A, Babatunde S. Type 2 diabetes in adult Nigerians: a study of its prevalence and risk factors in Port Harcourt, Nigeria. Diabetes Res Clin Pract, 2003; 62: 177-85.

7. Taurine Melnick JL., Enteroviruses: Polioviruses, Coxsackieviruses, Echoviruses and newer enteroviruses, 1996. 655-712. In Fields BN., Knipe DM., Hewley PM., Chanock RM.,Melnick JL., Month TP et. al., (Ed.)Virology, $3^{\text {rd }}$ ed. Lippiincott-Raven, Philadelphia. 
8. Modlin JF.,. Introduction, 1995. 1606-1613. In Mandell GL., Benneth JE., Dolin R.(Ed.), Principles and Practice of Infectious Diseases, $4^{\text {th }}$ ed. Churchill Livingstone, New York.

9. Theoklis Z., Joel DK. Enteroviruses infections. Paediatrics in Review,1998. 19: 183-190.

10. Oikarinen M, Tauriainen S, Honkanen T, Oikarinen S, Vuori K, Kaukinen K, Rantah I, Maki M, Hyoty H: Detection of enteroviruses in the intestine of type 1 diabetic patients. Clin Exp Immunol, 2008. 151: 71-75

11. Dider Hober.Enteroviral pathogenesis of type 1 diabetes http/ / www.discoverymedicine.com/dider hober (Accesed 27 September, 2011

12. Taurianen S, Oikarinen .S, Oikarinen .M, Hyoity. H. Enteroviruses in the pathogenesis of type 1 diabetes, semin immunopathol 2010

13. http://emedicine.medscape.com/article/919 999-overview (Accessed 12th December, 2011).

14. http://www.healthnewstrack.com/healthnews-1091.html (Accessed 15th January, 2012)..

15. Chehadeh W., Kerr-Conte J., Pattou F., Alm G., Lefebvre J., Wattre P., Hobber D. Persistent infection of human pancreatic islets by coxsackievirus B is associated with alpha interferon synthesis in beta cells. J. Virol, 2000. 74: 10153-10164.

16. Stewart TA, Hultgren B, Huang X, Pitts-Meek S, Hully J, MacLachlan NJ. Induction of type I diabetes by interferon-alpha in transgenic mice. Science. 1993.260:1942-6.

17. Viskari H, Knip M, Tauriainen S,. Maternal Enterovirus infection as a risk factor for type
1 diabetes in the exposed offspring, Diabetes care 2012. 35: 1328-1332.

18. http://www.esciencenews.com/articles/200 9/03/05/new.study.hun (Accessed 15th January, 2012).

19. http://www.phgfoundation.org/news/ (Acessed 12 February, 2012).

20. http://www.pms.ac.uk/pms/new.php?artic $\mathrm{le}=285$ (Accessed 10th November, 2011).

21. http://www.bornonigeria.com/index.php (Accessed 10th Deceber, 2011).

22. WHO Polio Laboratory Manual, 2004

23. Annals of the New York Academy of Sciences, 2003. Immunology of diabetes II: Pathogenesis from mouse to man, 1005; 1322.

24. Salminen, K. K., Vuorinen, T., Oikarinen, S., Helminen, M., Simell, S., Knip, M., Ilonen, J., Simell, O. and Hyöty, H. Isolation of enterovirus strains from children with preclinical Type 1 diabetes. Diabetic Medicine,2004. 21: 156-164.

25. Risérus U, Willett WC, Hu FB. "Dietary fats and prevention of type 2 diabetes". Progress in Lipid Research, 2009; 48 (1): 44-51.

26. Rigonan A s, Mann L, Chonmaitree: Use of monoclonal Antibodies to identify serotypes of enterovirus isolates. J Clin. Micrbiol, 1988. 26: 2576-2580.

27. Oderinde B S, Olabode A O, Harry T O, Baba M M, Bukbuk D N, Ogunmola O.O. Nonpolio Enterovirus Implicated in Acute flaccid paralysis in Northern Nigeria. Res $\mathrm{J}$ of $\mathrm{Med}$ and Med sci, 2007. 2(1); 25-28.

28. Coppieters Kt, Boettler T, and Von HerrathM . Virus infection in type 1 diabetes, Cold Spring Harb Perspect Med,2012. 2:a007732.

29. rrez D V, Oflendorfer E W, Ellis T M, Gauntt C J, Atkinson M A. Acceleration of type 1 diabetes by a coxsachievirus infection requires a pre-exsistin crictical mass of reactive T-cells in pancreatic islets. Diabetes, 2000. 49:708-711 